\title{
Abdominal aortic calcification in predialysis patients: Contribution of traditional and uremia-related risk factors
}

\author{
DELIA TIMOFTE ${ }^{1}$, DORIN DRAGOS ${ }^{2,3 *}$, ANDRA-ELENA BALCANGIU-STROESCU $^{1,4}$, \\ MARIA-DANIELA TĂNĂSESCU ${ }^{2,3}$, DANIELA GABRIELA BĂLAN ${ }^{4 *}$, LAURA RĂDUCU ${ }^{5,6}$, \\ ADRIAN TULIN $^{7,8}$, OVIDIU STIRU ${ }^{9,10^{*}}$ and DORIN IONESCU ${ }^{2,3^{*}}$
}

\begin{abstract}
${ }^{1}$ Department of Dialysis, Emergency University Hospital, 050098 Bucharest; ${ }^{2}$ Department of Medical Semiology, Discipline of Internal Medicine I and Nephrology, Faculty of Medicine, 'Carol Davila' University of Medicine and Pharmacy, 020021 Bucharest; ${ }^{3}$ Department of Nephrology, Emergency University Hospital, 050098 Bucharest; ${ }^{4}$ Discipline of Physiology, Faculty of Dental Medicine, ${ }^{5}$ Department of Plastic and Reconstructive Microsurgery, Faculty of Medicine, 'Carol Davila' University of Medicine and Pharmacy, 020021 Bucharest;

${ }^{6}$ Department of Plastic and Reconstructive Surgery, 'Prof. Dr. Agrippa Ionescu' Clinical Emergency Hospital, 011356 Bucharest; ${ }^{7}$ Department of Anatomy, Faculty of Medicine, 'Carol Davila' University of Medicine and Pharmacy, 020021 Bucharest; ${ }^{8}$ Department of General Surgery, 'Prof. Dr. Agrippa Ionescu' Clinical Emergency Hospital, 011356 Bucharest; ${ }^{9}$ Department of Cardiovascular Surgery, Faculty of Medicine,

'Carol Davila' University of Medicine and Pharmacy, 020021 Bucharest; ${ }^{10}$ Department of Cardiovascular Surgery, 'Prof. Dr. C.C. Iliescu' Emergency Institute for Cardiovascular Diseases, 022322 Bucharest, Romania
\end{abstract}

Received January 31, 2020; Accepted March 3, 2020

DOI: $10.3892 /$ etm.2020.8607

\begin{abstract}
Cardiovascular disease is the main cause of morbidity and mortality in end-stage renal disease (ESRD) patients. Recent population based epidemiological studies demonstrated a correlation between reduced renal function and risk for all causes
\end{abstract}

Correspondence to: Dr Delia Timofte, Department of Dialysis, Emergency University Hospital, Splaiul Independentei 169, 050098 Bucharest, Romania

E-mail: delia.timofte@gmail.com

*Contributed equally

Abbreviations: AAC, abdominal aorta calcifications; ACE, angiotensin I-converting enzyme; ADPKD, autosomal dominant polycystic kidney disease; BMI, body mass index; Cbfa1, core binding factor alpha 1; CERS2, ceramide synthase 2; CKD, chronic kidney disease; $\mathrm{CRP}, \mathrm{C}$ reactive protein; $\mathrm{CT}$, computed tomography; DEXA, dual-energy X-ray absorptiometry; EBCT, electron beam computed tomography; ESRD, end-stage renal disease; GFR, glomerular filtration rate; $\mathrm{Hb}$, hemoglobin; HD, hemodialysis; HTA, hypertension; i.q.r., interquartile range; KDOQI, Kidney Disease Outcomes Quality Initiative; M, male; MDRD, modification of diet in renal disease; NS, not significant; RAO, retinal artery occlusion; $\mathrm{SD}$, standard deviation; VC, vascular calcifications; VSMCs, vascular smooth muscle cells

Key words: chronic kidney disease, end stage renal disease, predialysis, vascular calcification, lateral plain radiograph of the abdomen, abdominal aortic calcification score and cardiovascular mortality, $50 \%$ of patients dying before the commencement of renal replacement therapy. Vascular calcifications (VC) and arterial stiffness are major contributors to cardiovascular disease and are independent predictors of cardiovascular mortality in ESRD patients. Scarce information is available on the risk factors and prognosis of predialysis patients with VC. The aim of this study was to evaluate the contribution of traditional and uremia related risk factors to abdominal aortic calcification in predialysis patients. A single center, retrospective study was performed on 305 adult patients monitored at the Bucharest University Emergency Hospital for at least 6 months. Our study reports an increased incidence of $\mathrm{VC}$ in predialysis chronic kidney disease (CKD) patients, higher in those with advanced age, history of cardiovascular disease, osteoporosis, and declining renal function.

\section{Introduction}

The increase in the number of hypertensive and diabetic patients globally leads to an increase in the prevalence of CKD. Over time, high blood pressure and diabetes can lead to kidney damage (1-3). High blood pressure may occur as a consequence of CKD induced by another pathology (4).

Recent studies in the literature demonstrate the important role of the genetic factors in the development of diabetic nephropathy relating to the angiotensin I-converting enzyme (ACE) gene, the ceramide synthase 2 (CERS2) gene and the genetic polymorphism of vitamin $\mathrm{D}$ receptors. The fundamental role of glucose transporter 2, growth factor $\beta$ and endothelial nitric oxide synthase has also been demonstrated in the development of diabetic nephropathy (5). 
The close association between CKD and cardiovascular disease is responsible for the increased mortality rate of CKD patients. The survival is also influenced by their nutritional and inflammatory status (6).

Cardiovascular disease is the main cause of morbidity and mortality in ESRD patients (7). The presence of overt cardiovascular disease and its risk factors at the initiation of dialysis suggest a high incidence of cardiovascular disease in predialysis patients (8). Recent population based epidemiological studies demonstrated a correlation between reduced renal function and the risk for all causes and cardiovascular mortality, a high proportion of patients dying before receiving dialysis (9).

Literature indicates that a rise in $\mathrm{VC}$ prevalence is associated with the decline of glomerular filtration rate (GFR) (10). VC and arterial stiffness are major contributors to cardiovascular disease and are independent predictors of cardiovascular mortality in ESRD patients (11).

CKD patients develop accelerated medial as well as intimal calcification and this calcification rapidly progresses in patients on dialysis (12). VC prevalence is high in chronic hemodialysis (HD) patients. An observational multicentric study describes the presence of VC in $100 \%$ of studied patients (13).

Patients with CKD and general aging population have VC in common, which is an active process. Transdifferentiation of vascular smooth muscle cells (VSMCs) to osteoblast-like cells via upregulation of core binding factor alpha 1 (Cbfa1) is one of the first steps in arterial calcification. These differences can appear due to elevated serum phosphorus or other yet unidentified uremic toxins. Whereas, a protective role has been described for serum fetuin-A and other inhibitors of the calcification process. Deeper understanding of the pathogenesis of VC will allow the development of therapeutic strategies to arrest this process (11).

Scarce information is available on risk factors and prognosis of VC in predialysis patients (14). The aim of this study was to evaluate the contribution of traditional and uremia related risk factors to abdominal aortic calcification in predialysis patients.

This study was approved by Ethics Committee of the Emergency University Hospital of Bucharest (Romania). Written informed consent was obtained from the patients prior to publication.

\section{Patients and methods}

Study design. A single center, retrospective study was performed on 305 adult patients monitored at the Bucharest University Emergency Hospital for at least 6 months. The inclusion criteria were age $>18$ years and a diagnosis of CKD, defined as a GFR decline (GFR $\left.<60 \mathrm{ml} / \mathrm{min} / 1.73 \mathrm{~m}^{2}\right)$ present for $>6$ months associated with one of the following: albuminuria (urine albumin-creatinine ratio $\geq 30 \mathrm{mg} / \mathrm{g}$ ), urine sediment abnormalities, electrolyte and other abnormalities due to tubular disorders, histological abnormalities, structural abnormalities detected by imaging, or history of kidney transplantation (15).

Patients with neoplastic, infectious or inflammatory diseases were excluded. All the 305 patients included in the study had a lateral abdominal X-ray performed, which was employed for calculating aortic calcification score and for diagnosing osteoporosis. For all these patients, data were collected from the patient's charts at enrollment, including demographic and clinical data [age, sex, smoking habits, primary renal disease, and a history of cardiovascular disease characterized by the presence of one of the following: myocardial infarction, angina pectoris, coronary artery revascularization, stroke or positive diagnostic procedure result (stress test, coronary or peripheral angiography)] and laboratory data (see below). As these demographic, clinical, and laboratory data are routinely collected for any monitored CKD patient, there were no missing data, consequently no patient was excluded on this account.

Laboratory data. X-ray examinations were performed at the time of the study. Laboratory data were retrieved from the patient files for the previous 6 months. Blood samples were drawn in the fasting state for determination of serum levels of creatinine, urea, cholesterol, triglycerides, calcium, phosphate, albumin, fibrinogen and $\mathrm{C}$ reactive protein (CRP). GFR was calculated according to modification of diet in renal disease (MDRD) 4 formula. The study population was grouped according to the stages of CKD, in keeping with Kidney Disease Outcomes Quality Initiative (KDOQI) guidelines. Time, averaged values, over the previous 6 months were used for analyses.

Abdominal aorta calcification score. A semi-quantitative scoring system assigning 1-3 points to areas of calcification identified along the anterior or posterior surface of the aorta extending from the 1st to the 4th lumbar vertebra on a lateral plain radiograph of the abdomen, as originally described by Kauppilla et al (16), was used. Eight locations were evaluated (anterior and posterior abdominal aortic walls of the four aortic segments corresponding to the four lumbar vertebrae L1 to L4) by lateral abdominal radiographs and assigned Framingham calcification scores $(0$, no detectable calcification; 1 , small scattered calcifications involving $1 / 3$ of aortic segment; 2 , calcification involving $1 / 3$ to $<2 / 3$ of the aortic segment, 3 , calcification involving $2 / 3$ of the aortic segment). With this method, the score could vary from a minimum of 0 to a maximum of 24 points. Scores were grouped into four categories: 0 (107 patients), 1-3 (47 patients), 3-10 (86 patients), >10 (65 patients). All X-rays were read by three independent reciprocally blinded investigators and a consensus was reached on the interpretation of all films. The diagnosis of osteoporosis is radiological on the same X-ray where abdominal aortic calcification score was estimated.

Statistical analysis. Data are presented as mean and standard deviation (SD) or as median and inter-quartiles range, according to distribution. Univariable and multivariable analysis, e.g. multiple linear regression (estimated as $\mathrm{R}^{2}$ ) were used to investigate the correlations between aortic calcification score and several other study parameters, classified as traditional (sex, age, hypertension (HTA), smokers, triglycerides, cholesterol, glucose, cardiovascular comorbidities) and non-traditional [vascular nephropathy, phosphocalcic metabolism disorders, body mass index (BMI), CRP, 
Table I. Characteristics of patients $(n=305)$.

\begin{tabular}{|c|c|}
\hline Parameters & Value \\
\hline Age (years; median, range) & $62(53-73)$ \\
\hline Sex (\% males) & 50.5 \\
\hline Smoking (\%) & 45.0 \\
\hline \multicolumn{2}{|l|}{ Primary renal disease $(\%)$} \\
\hline Vascular disease & 44.3 \\
\hline Glomerular nephropathies & 30.5 \\
\hline Interstitial nephropathies & 13.8 \\
\hline Diabetes nephropathies & 7.2 \\
\hline ADPKD & 3.0 \\
\hline GFR (median; i.q.r) & $28.4(11.4-48.6)$ \\
\hline Stage $1,2(\%)$ & 14.8 \\
\hline Stage $3(\%)$ & 33.4 \\
\hline Stage $4(\%)$ & 19.0 \\
\hline Stage $5(\%)$ & 32.8 \\
\hline Hypertension (\%) & 73.4 \\
\hline \multicolumn{2}{|l|}{ Cardio-vascular co-morbidities (\%) } \\
\hline Ischemic heart disease & 35.0 \\
\hline Cerebrovascular & 7.0 \\
\hline Peripheral vascular disease & 21.3 \\
\hline Cholesterol >200 mg/dl (\%) & 50.0 \\
\hline Triglycerides >150 mg/dl (\%) & 40.0 \\
\hline Glucose level (median, i.q.r) & $102(91-116)$ \\
\hline BMI (median i.q.r) & $26(24-31)$ \\
\hline $\mathrm{BMI}<20(\%)$ & 8.9 \\
\hline BMI 20-25 (\%) & 26.6 \\
\hline BMI 25-30 (\%) & 36.1 \\
\hline $\mathrm{BMI}>30(\%)$ & 28.5 \\
\hline Inflammation (CRP > 3 mg/l; \%) & 77.0 \\
\hline Aortic calcification score; median (i.q.r.) & $3(0-10)$ \\
\hline Osteoporosis (\%) & 50.0 \\
\hline \multicolumn{2}{|l|}{ Serum calcium } \\
\hline $\begin{array}{l}\text { Time-averaged (mg/dl per month; } \\
\text { mean } \pm \text { SD) }\end{array}$ & $8.7 \pm 1.1$ \\
\hline \multicolumn{2}{|l|}{ Serum phosphate } \\
\hline $\begin{array}{l}\text { Time-averaged }(\mathrm{mg} / \mathrm{dl} \text { per month; } \\
\text { mean } \pm \mathrm{SD})\end{array}$ & $4.8 \pm 2.0$ \\
\hline
\end{tabular}

ADPKD, autosomal dominant polycystic kidney disease; GFR, glomerular filtration rate; BMI, body mass index; CRP, $\mathrm{C}$ reactive protein; $\mathrm{SD}$, standard deviation.

osteoporosis] risk factors. Logistic regression was performed in the case of categorical parameters: sex, HTA, smoking, cardiovascular comorbidities, vascular nephropathy and osteoporosis. The numerical parameters (age, triglycerides, cholesterol, glucose, calcium, phosphates, calcium phosphate product, BMI, CRP) were adjusted by normalization before performing the multiple linear regression.

Comparisons among the four categories of aortic calcification score were made by means of Chi-square test (when the associations with categorical parameters were analyzed) or ANOVA and Willcoxon or Mann-Whitney test (when the associations with numerical parameters were analyzed). All analyses were performed using EPIINFO6 and GraphPad InStat 2003.

\section{Results}

There was a slight male $(\mathrm{M})$ preponderance $(50.5 \%)$. The median age was 62 years, and $43.3 \%$ of patients were aged $>65$ years. Smoking prevalence was $45 \%$ (Table I). A history of cardiovascular disease was present in $64.3 \%$ of patients. The primary renal diseases were vascular nephropathy $(44.3 \%)$, followed by glomerular nephropathies $(30.5 \%)$ and interstitial nephropathy (13.8\%). Diabetic kidney disease was present in $7.2 \%$ of patients. The median GFR was $28.45 \mathrm{ml} / \mathrm{min} / 1.73 \mathrm{~m}^{2}$ (range, 11.4-48.6). 14.8\% of patients was in stage 1 and 2 of CKD; $33.4 \%$ in stage 3; $19 \%$ in stage 4 and $32.8 \%$ in stage 5 . HTA was present in $73.4 \%$ of the patients. Total cholesterol levels were $>200 \mathrm{mg} / \mathrm{dl}$ in $50 \%$ of patients; triglycerides were $>150 \mathrm{mg} / \mathrm{dl}$ in $40 \%$ of patients. Although the mean hemoglobin $(\mathrm{Hb})$ value was in the normal range $(112.2 \mathrm{~g} / \mathrm{dl})$, anemia $(\mathrm{Hb}<11 \mathrm{~g} / \mathrm{dl})$ was observed in $50 \%$ of patients, all of whom had stage 3,4 or 5 CKD. The median BMI was $26 \mathrm{~kg} / \mathrm{m}^{2}$ (24-31) with $64.6 \%$ of patients overweight and obese. Only $8.9 \%$ of patients had BMI $<20 \mathrm{~kg} / \mathrm{m}^{2}$. The median CRP was 12 (4-43), only $23 \%$ of patients had CRP $<3 \mathrm{mg} / \mathrm{l}$ and $56 \%$ with CRP $>10 \mathrm{mg} / \mathrm{l}$. The mean albumin level was $3.7 \pm 0.4 \mathrm{mg} / \mathrm{dl}$, with $50 \%$ of the patients with albumin $<4 \mathrm{~g} / \mathrm{dl}$. Bone mineral metabolism was altered by CKD, hyperphosphatemia and hypocalcemia was present in 25.5 and $28 \%$ of patients. In the whole group, median aortic calcification score was 3 (i.q.r. 0-10) and in 35.1\% the score was $0.50 \%$ of the patients with a diagnosis of osteoporosis on X-ray examination.

In univariable analysis, higher aortic calcification scores were associated with older age, smoking, HTA, glucose level, a history of cardiovascular disease, vascular nephropathy, 'macro inflammation', e.g. CRP >10 mg/l, osteoporosis and GFR (Table II).

A model of multiple linear regression including all relevant parameters resulting from univariate analysis explained $34 \%$ of aortic calcification score. In this model, age $(\mathrm{r}=3, \mathrm{P}=0.0024)$, a history of cardiovascular disease $(r=3.7, P=0.0002)$, osteoporosis $(\mathrm{r}=4.39, \mathrm{P}<0.0001)$, and GFR $(\mathrm{r}=2, \mathrm{P}=0.04)$ were significantly associated with aortic calcification (Table III).

\section{Discussion}

Vascular calcification (VC) is common in CKD and is associated with increased morbidity and mortality (10). In the published studies, a close link between aortic calcification, valvular calcifications and carotid plaques was observed (17). Also, studies describe a tight association between atherosclerotic plaques and retinal artery occlusion (RAO). This is why retina blood vessel anomalies are described in ESRD patients (18). A viable treatment option for RAO is Nd:Yag laser embolysis (19).

Arterial calcification is clinically detected through a number of techniques including plain radiographs, ultrasonography, tomography, scintigraphy and computed tomography (CT) scan, more recently by electron beam 
Table II. Distribution of investigated parameters according to the four categories of aortic score calcification (NS, P $>0.05$ ).

Categories according to aortic calcification score

Parameters

Aortic calcification score

\begin{tabular}{|c|c|c|c|c|}
\hline 0 & $1-3$ & $3-10$ & $>10$ & $\mathrm{P}$ trend \\
\hline 107 & 47 & 86 & 65 & \\
\hline 50.5 & 44.7 & 58.1 & 44.6 & NS \\
\hline $51.6 \pm 13.9$ & $62.9 \pm 10.7$ & $66.8 \pm 11.2$ & $72.0 \pm 10.4$ & 0.004 \\
\hline 66.4 & 85.1 & 70.9 & 80.0 & 0.05 \\
\hline 25.0 & 30.0 & 38.0 & 48.0 & 0.05 \\
\hline $139(98-189)$ & $125(105-232)$ & $135(102-184)$ & $140(101-175)$ & NS \\
\hline $198(167-245)$ & $220(175-284)$ & $198(160-243)$ & $201(175-228)$ & NS \\
\hline 99 (89-107) & $101(89-123)$ & $103(93-122)$ & $105(97-122)$ & 0.05 \\
\hline 31.8 & 74.5 & 75.6 & 95.4 & 0.0008 \\
\hline 26.2 & 48.9 & 48.8 & 64.6 & 0.05 \\
\hline $37.3 \pm 29.6$ & $34.9 \pm 24.3$ & $34.0 \pm 25.2$ & $25.6 \pm 20.6$ & 0.04 \\
\hline $8.5 \pm 1.5$ & $8.8 \pm 1.0$ & $9.0 \pm 0.9$ & $8.7 \pm 0.9$ & NS \\
\hline $5.2 \pm 2.3$ & $4.9 \pm 2.0$ & $4.6 \pm 1.5$ & $4.8 \pm 1.9$ & NS \\
\hline $41.7 \pm 14.5$ & $41.6 \pm 13.2$ & $40.3 \pm 11.4$ & $41.2 \pm 15.5$ & NS \\
\hline $27.4 \pm 6.4$ & $28.5 \pm 5.9$ & $27.1 \pm 6.3$ & $27.3 \pm 5.4$ & NS \\
\hline 54.2 & 40.4 & 67.4 & 68.0 & 0.05 \\
\hline 18.7 & 48.9 & 62.8 & 85.9 & 0.0001 \\
\hline
\end{tabular}

Number of patients

Traditional risk factors

$\operatorname{Sex}(\mathrm{M})(\%)$

Age (years; mean $\pm \mathrm{SD}$ )

$\operatorname{HTA}(\%)$

Smokers (\%)

Triglycerides; mg/dl, median (i.q.r)

Cholesterol; mg/dl, median (i.q.r)

Glucose; mg/dl, median (i.q.r)

CV comorbidity (\%)

Non-traditional risk factors

Vascular nephropathy (\%)

Mean GFR ( $\mathrm{ml} / \mathrm{min})$

Calcium, time-averaged \pm SD $(\mathrm{mg} / \mathrm{dl})$

Phosphates; time-averaged $\pm \mathrm{SD}(\mathrm{mg} / \mathrm{dl})$

Calcium phosphate product; time-averaged $\pm \mathrm{SD}$ ) $\left(\mathrm{mg}^{2} / \mathrm{dl}^{2}\right)$

BMI $\left(\mathrm{kg} / \mathrm{m}^{2}\right)($ mean$)$

CRP; (\%) CRP >10 mg/l

Osteoporosis $(\%)$

18.7

48.9

62.8

0.0001

NS, not significant; M, male; SD, standard deviation; HTA, hypertension; GFR, glomerular filtration rate; BMI, body mass index; CRP, C reactive protein.

Table III. Relationships of aortic calcification score with the investigated parameters by multiple linear regression $\left(\mathrm{R}^{2}=0.34\right)$ with aortic calcification score as dependent variable.

\begin{tabular}{lccc}
\hline Independent variables & $\beta$ & $95 \%$ Confidence interval & P-value \\
\hline Age (years) & 0.08 & $0.02-0.13$ & 0.0024 \\
Smoking & 1.46 & $-0.24-3.15$ & 0.10 \\
Vascular etiology & -0.04 & $-0.11-0.02$ & 0.22 \\
CV comorbidity & 2.79 & $1.33-4.26$ & 0.0002 \\
HTA & -0.12 & $-1.51-1.26$ & 0.85 \\
GFR & -0.02 & $-0.04-0.0005$ & 0.04 \\
Osteoporosis & 3.197 & $1.77-4.62$ & $<0.0001$ \\
CRP $>10 \mathrm{mg} / 1$ & 1.36 & $0.8-1.5$ & 0.55 \\
Glucose & 0.01 & $-0.006-0.03$ & 0.18 \\
\hline
\end{tabular}

GFR, glomerular filtration rate; $\mathrm{CRP}, \mathrm{C}$ reactive protein.

computed tomography (EBCT) and multislice CT. The last two techniques permit reproducible quantification of coronary arteries and aorta calcification, but still do not allow differentiation between the intimal or medial site of calcification and are very expensive.

The Global Bone and Mineral Initiative (20) proposed a series of simple in-office measurements and assessments as substitutes for EBCT and multidetector CT to identify and semiquantitatively evaluate the extent of cardiovascular calcifications in ESRD patients. This group of experts suggested that a plain lateral X-ray of the lumbar spine to assess the calcification of the abdominal aorta, the measurement of pulse pressure, and an echocardiogram to visualize calcification of the cardiac valves might provide useful diagnostic and 
prognostic information (21). It has been demonstrated that aortic calcification score shows a very good correlation with EBT measurements (22).

In HD patients, the presence of abdominal aorta calcifications (AAC) predicts coronary artery disease (23) and cardiovascular mortality (24). This is the first study that evaluates AAC by Kauppila score in predialysis patients and the contribution of traditional and nontraditional risk factors. Our study indicates that the prevalence of $\mathrm{VC}$ in predialysis patients is high. The prevalence of $\mathrm{VC}$ reported in predialysis population is $40-90 \%$, depending on the site of VC evaluated, age, presence of diabetes, cardiovascular comorbidities, and degree of renal dysfunction $(25,26)$.

In published studies the prevalence of $\mathrm{VC}$ was lower for younger patients, with neither diabetes, nor cardiovascular comorbidities, and higher for older diabetic patients with cardiovascular comorbidity (14,27-29). In our study, where the patients are older, obese, and with many cardiovascular comorbidities, the prevalence of $\mathrm{VC}$ is $65 \%$.

In the present study, patients with AAC were older and more frequently smokers, and had HTA, a history of cardiovascular disease, and a higher fasting blood glucose level. Similarly to the studies cited above, we found a strong correlation of AAC with increasing age, and similarly to the study by Tomiyama et al (14), with HTA and a higher blood glucose. The association between AAC and an elevated level of fasting glucose suggests the contribution of insulin resistance, and in a recent study by Kobayashi et al (30) contributed to coronary artery calcification in predialysis patients. Contrary to the study by Toussaint et al (31) and Tomiyama et al (14), TG levels were not an independent determinant of VC in our study.

Among non-traditional risk factors, macroinflammation is associated in univariate analysis with VC (32). Ross (33) stated that atherosclerosis is an inflammatory disease. In CKD patients, inflammation is one of the key mediators of vessel wall calcification (34). In predialysis patients, severe coronary calcifications were associated with sFAS, a marker of inflammation, in the study of Tomiyama et al (14). In our study, high prevalence of inflammation in predialysis patients, was higher than the $30-50 \%$ reported in HD patients (35). Besides, the high burden of cardiovascular comorbidity and a high percent of patients in stage $5 \mathrm{CKD}$, the high prevalence of obesity in our patients, reported also in other studies, can be a plausible explanation. Abnormalities in calcium and phosphorus metabolism influence the development and progression of VC in CKD patients (10). Similarly to HD patients, where not all studies demonstrated an association between abnormality in mineral metabolism and VC, also in studies done on predialysis patients the results were contradictory. Our study did not find an association between AAC and the blood level of calcium or phosphorus, or calcium-phosphate product.

CKD has been individualized as an independent risk factor for $\mathrm{CV}$ disease, proportionally with the decline in renal function. In the studies by Fox et al (36), Kramer et al (28), Kobayashi et al (30) and Toussaint et al (31), there was an association between VC and declining renal function in the unadjusted analysis. However, in the multiple logistic regression analysis, after adjusting for age, diabetes, sex, race, HTA, and IL6, the association was lost. In our study based on an anadjusted analysis, the VC score is higher in patients with lower GFR. Bone ill-health is correlated with VC (37) particularly in patients with CKD $(38,39)$.

There are many studies demonstrating the association between the bone quality [as evaluated by histomorphometry, radiology, ultrasonography, computerized tomography or dual-energy X-ray absorptiometry (DEXA)] and VC in HD patients $(40,41)$. In predialysis patients there is a study by Toussaint et al (31) demonstrating an inverse correlation between femoral arterial calcifications and femoral T score (31). In our study, although the diagnosis of osteoporosis was made by X-ray, which picks up only the advanced stage, a strong correlation with VC was found, similar to the general population.

In conclusion, this study reports a high incidence of $\mathrm{VC}$ in predialysis CKD patients, worse with age, a history of cardiovascular disease, presence of osteoporosis and deteriorating renal function.

\section{Acknowledgements}

Not applicable.

\section{Funding}

No funding was received.

\section{Availability of data and materials}

The datasets used and/or analyzed during the present study are available from the author on reasonable request.

\section{Authors' contributions}

DT, DD and DI designed the study, obtained the data, and were responsible for the clinical management of the patient, the data evaluation and analysis and the writing of the manuscript. DT, AEBS and MDT analyzed and interpreted the X-rays. DT, DGB, LR, AT and OS performed the literature search and selected the studies to be included. DI and DD critically revised the manuscript. All authors read and approved the final manuscript. The contributions of all the authors on this article are greatly valued and appreciated.

\section{Ethics approval and consent to participate}

This study was approved by Ethics Committee of the Emergency University Hospital of Bucharest (Romania). Written informed consent was obtained from the patients prior to publication.

\section{Patient consent for publication}

Not applicable.

\section{Competing interests}

The authors declare that they have no competing interests.

\section{References}

1. Ghaderian SB and Beladi-Mousavi SS: The role of diabetes mellitus and hypertension in chronic kidney disease. J Renal Inj Prev 3: 109-110, 2014. 
2. Balan DG, Balcangiu Stroescu AE, Tanasescu MD Diaconescu A, Raducu L, Mihai A, Tanase M, Stanescu II and Ionescu D: Nutritional intervention in patients with diabetic renal disease - A brief presentation. Rev Chim 69: 3178-3182, 2018.

3. Savoiu Balint G, Iovanescu G, Stanca HT, Popoiu CM, Boia E, Popovici RA and Bolintineanu SL: The protective effect of HDL-cholesterol in patients with essential hypertension. Rev Chim (Bucharest) 68: 949-952, 2017.

4. Mandita A, Timofte D, Balcangiu-Stroescu AE, Balan D, Raducu L, Tanasescu MD, Diaconescu A, Dragos D, Cosconel CI, Stoicescu SM and Ionescu D: Treatment of high blood pressure in patients with chronic renal disease. Rev Chim 70: 993-995, 2019.

5. Balcangiu Stroescu AE, Tanasescu MD, Diaconescu A, Raducu L, Balan DG, Mihai A, Tanase M, Stanescu II and Ionescu D: Diabetic nephropathy: A concise assessment of the causes, risk factors and implications in diabetic patients. Rev Chim 69: 3118-3121, 2018.

6. Balcangiu Stroescu AE, Tanasescu MD, Diaconescu A, Raducu L, Constantin AM, Balan DG, Tarmure V and Ionescu D: Cardiovascular comorbidities, inflammation and serum albumin levels in a group of hemodialysis patients. Rev Chim 69: 926-929, 2018.

7. Levin A: Clinical epidemiology of cardiovascular disease in chronic kidney disease prior to dialysis. Semin Dial 16: 101-105, 2003.

8. Wheeler DC, Townend JN and Landray MJ: Cardiovascular risk factors in predialysis patients: Baseline data from the Chronic Renal Impairment in Birmingham (CRIB) study. Kidney Int 63 (Suppl. 84): S201- S203, 2003.

9. Caravaca F, Chávez E, Alvarado R, García-Pino G and Luna E: Sudden cardiac death in non-dialysis chronic kidney disease patients. Nefrologia 36: 404-409, 2016.

10. Palit S and Kendrick J: Vascular calcification in chronic kidney disease: Role of disordered mineral metabolism. Curr Pharm Des 20: 5829-5833, 2014

11. Moe SM and Chen NX: Pathophysiology of vascular calcification in chronic kidney disease. Circ Res 95: 560-567, 2004.

12. Bellasi A, Kooienga L, Block GA, Veledar E, Spiegel DM and Raggi P: How long is the warranty period for nil or low coronary artery calcium in patients new to hemodialysis? J Nephrol 22: 255-262, 2009

13. Kraus MA, Kalra PA, Hunter J, Menoyo J and Stankus N: The prevalence of vascular calcification in patients with end-stage renal disease on hemodialysis: A cross-sectional observational study. Ther Adv Chronic Dis 6: 84-96, 2015.

14. Tomiyama C, Higa A, Dalboni MA, Cendoroglo M, Draibe SA, Cuppari L, Carvalho AB, Neto EM and Canziani ME: The impact of traditional and non-traditional risk factors on coronary calcification in pre-dialysis patients. Nephrol Dial Transplant 21: 2464-2471, 2006.

15. National Kidney Foundation: K/DOQI clinical practice guidelines for chronic kidney disease: evaluation, classification, and stratification. Am J Kidney Dis 39 (2 Suppl 1): S1-S266, 2002

16. Kauppila LI, Polak JF, Cupples LA, Hannan MT, Kiel DP and Wilson PW: New indices to classify location, severity and progression of calcific lesions in the abdominal aorta: A 25-year follow-up study. Atherosclerosis 132: 245-250, 1997.

17. Timofte D, Ionescu D, Medrihan L, Rasina A and Damian L: Vascular calcification and bone disease in hemodialysis patient, assessment, association and risk factors. Nephrol Dial Transplant 22: 325-326, 2007.

18. Chang YS, Weng SF, Chang C, Wang JJ, Tseng SH, Ko SY, Su SB, Huang CC, Wang JY and Jan RL: Risk of retinal artery occlusion in patients with end-stage renal disease: A retrospective large-scale cohort study. Medicine (Baltimore) 95: e3281, 2016.

19. Stanca HT, Petrović Z and Munteanu M: Transluminal Nd:YAG laser embolysis - a reasonable method to reperfuse occluded branch retinal arteries. Vojnosanit Pregl 71: 1072-1077, 2014.

20. Moe SM and Drüeke T: Improving global outcomes in mineral and bone disorders. Clin J Am Soc Nephrol 3 (Suppl. 3): S127-S130, 2008.

21. Muntner P, Ferramosca E, Bellasi A, Block GA and Raggi P: Development of a cardiovascular calcification index using simple imaging tools in haemodialysis patients. Nephrol Dial Transplant 22: 508-514, 2007.

22. Bellasi A, Ferramosca E, Muntner P, Ratti C, Wildman RP, Block GA and Raggi P: Correlation of simple imaging tests and coronary artery calcium measured by computed tomography in hemodialysis patients. Kidney Int 70: 1623-1628, 2006.
23. Chen HC, Wang WT, Hsi CN, Chou CY, Lin HJ, Huang CC and Chang CT: Abdominal aortic calcification score can predict future coronary artery disease in hemodialysis patients: A 5-year prospective cohort study. BMC Nephrol 19: 313, 2018.

24. Okuno S, Ishimura E, Kitatani K, Fujino Y, Kohno K, Maeno Y, Maekawa K, Yamakawa T, Imanishi Y, Inaba M, et al: Presence of abdominal aortic calcification is significantly associated with all-cause and cardiovascular mortality in maintenance hemodialysis patients. Am J Kidney Dis 49: 417-425, 2007.

25. Górriz JL, Molina P, Cerverón MJ, Vila R, Bover J, Nieto J, Barril G, Martínez-Castelao A, Fernández E, Escudero V, et al: Vascular calcification in patients with nondialysis CKD over 3 years. Clin J Am Soc Nephrol 10: 654-666, 2015.

26. Watanabe R, Lemos MM, Manfredi SR, Draibe SA and Canziani MEF: Impact of cardiovascular calcification in nondialyzed patients after 24 months of follow-up. Clin J Am Soc Nephrol 5: 189-194, 2010.

27. Garland JS, Holden RM, Groome PA, Lam M, Nolan RL, Morton AR and Pickett W: Prevalence and associations of coronary artery calcification in patients with stages 3 to 5 CKD without cardiovascular disease. Am J Kidney Dis 52: 849-858, 2008.

28. Kramer H, Toto R, Peshock R, Cooper R and Victor R: Association between chronic kidney disease and coronary artery calcification: The Dallas Heart Study. J Am Soc Nephrol 16: 507-513, 2005 .

29. Kestenbaum BR, Adeney KL, de Boer IH, Joachim HIx, Shlipak MG and Siscovick DS: Incidence and progression of coronary calcification in chronic kidney disease: The Multi-Ethnic Study of Atherosclerosis. Kidney Int 76: 991-998, 2009.

30. Kobayashi S, Oka M, Maesato K, Ikee R, Mano T, Hidekazu M and Ohtake T: Coronary artery calcification, ADMA, and insulin resistance in CKD patients. Clin J Am Soc Nephrol 3: 1289-1295, 2008.

31. Toussaint ND, Lau KK, Strauss BJ, Polkinghorne KR and Kerr PG: Associations between vascular calcification, arterial stiffness and bone mineral density in chronic kidney disease. Nephrol Dial Transplant 23: 586-593, 2008.

32. Kraśniak A, Drozdz M, Pasowicz M, Chmiel G, Michałek M, Szumilak D, Podolec P, Klimeczek P, Konieczyńska M, Wicher-Muniak E, et al: Factors involved in vascular calcification and atherosclerosis in maintenance haemodialysis patients. Nephrol Dial Transplant 22: 515-521, 2007.

33. Ross R: Atherosclerosis - an inflammatory disease. N Engl J Med 340: 115-126, 1999.

34. Benz K, Hilgers KF, Daniel C and Amann K: Vascular calcification in chronic kidney disease: The role of inflammation. Int $\mathrm{J}$ Nephrol 2018: 4310379, 2018.

35. Jofré R, Rodriguez-Benitez P, López-Gómez JM and Pérez-Garcia R: Inflammatory syndrome in patients on hemodialysis. J Am Soc Nephrol 17 (Suppl. 3): S274-S280, 2006.

36. Fox CS, Larson MG, Keyes MJ, Levy D, Clouse ME, Culleton B and O'Donnell CJ: Kidney function is inversely associated with coronary artery calcification in men and women free of cardiovascular disease: The Framingham Heart Study. Kidney Int 66: 2017-2021, 2004

37. Cannata-Andia JB, Roman-Garcia P and Hruska K: The connections between vascular calcification and bone health. Nephrol Dial Transplant 26: 3429-3436, 2011.

38. Moe SM: Vascular calcification and renal osteodystrophy relationship in chronic kidney disease. Eur J Clin Invest 36 (Suppl. 2): 51-62, 2006.

39. Demer L and Tintut Y: The bone-vascular axis in chronic kidney disease. Curr Opin Nephrol Hypertens 19: 349-353, 2010.

40. London GM, Marty C, Marchais SJ, Guerin AP, Metivier F and de Vernejoul MC: Arterial calcifications and bone histomorphometry in end-stage renal disease. J Am Soc Nephrol 15: 1943-1951, 2004

41. Adragao T, Herberth J, Monier-Faugere MC, Branscum AJ, Ferreira A, Frazao JM, Dias Curto J and Malluche HH: Low bone volume - a risk factor for coronary calcifications in hemodialysis patients. Clin J Am Soc Nephrol 4: 450-455, 2009.

This work is licensed under a Creative Commons Attribution-NonCommercial-NoDerivatives 4.0 International (CC BY-NC-ND 4.0) License. 